\title{
Corpus
}

Archivos virtuales de la alteridad americana

Vol. 9, No 2 | 2019

Julio / Diciembre 2019

\section{Actitud Bayer}

\section{Diana Lenton}

\section{OpenEdition}

Journals

Electronic version

URL: http://journals.openedition.org/corpusarchivos/3354

ISSN: 1853-8037

\section{Publisher}

Diego Escolar

Electronic reference

Diana Lenton, « Actitud Bayer », Corpus [En línea], Vol. 9, No 2 | 2019, Publicado el 27 diciembre 2019, consultado el 28 diciembre 2019. URL : http://journals.openedition.org/corpusarchivos/3354

This text was automatically generated on 28 December 2019.

Licencia Creative Commons: Atribución-NoComercial 2.5 Argentina (CC BY-NC 2.5 AR) 


\title{
Actitud Bayer $^{1}$
}

\author{
Diana Lenton
}

1 En estos días se cumple el primer aniversario del fallecimiento de Osvaldo Bayer, periodista, escritor, guionista e historiador.

2 Lo conocí en 2005, cuando una legisladora porteña del Bloque 19 y 20 convocó a la Red de Investigadores en Genocidio y Política Indígena, creada poco tiempo antes, para organizar una serie de jornadas que, por primera vez en ese ámbito, discutieron sobre el genocidio sufrido por los pueblos originarios en la Argentina. En esas jornadas Osvaldo participó en su carácter de autor del proyecto de ley-sucesivamente archivado y vuelto a presentar- que dispone retirar de la Ciudad de Buenos Aires el monumento a Julio Argentino Roca -el militar que protagonizó la avanzada más encarnizada contra los indígenas-. A partir de entonces iniciamos una relación de colaboración y amistad por la que estaré siempre agradecida.

3 Durante años, todos los jueves, después de la Ronda de las Madres de Plaza de Mayo, Osvaldo se dirigía al monumento mayor al General Roca en la Avenida Diagonal Sur para explicar a viva voz los motivos del proyecto y por qué es imprescindible desmonumentar el relato histórico para hacer justicia con las víctimas del genocidio. Con lluvia o con sol, lo acompañaba un grupo estable de activistas que conformaron el grupo Awka Liwen (Rebelde Amanecer en lengua mapuche). También se acercaban representantes de otros grupos con búsquedas similares en torno a lo que Bayer definía como una renovación ética que incluyera una nueva interpretación de la historia. Enfrentado a la estimación estadística de la "eficacia" de su prédica, Bayer sostuvo que aún si se lograra llamar la atención de sólo cuatro o cinco transeúntes por semana, al cabo de un año habría al menos, varios cientos de ciudadanos abiertos a una nueva concepción del problema. El trabajo hormiga encarado por Bayer tuvo su correlato entonces en las intervenciones anónimas que comenzaron a ocurrir sobre los monumentos a Roca y a otros representantes del statu quo en todo el país, igualmente efímeras y eficaces. En diferentes ciudades se presentaron proyectos de ley para renombrar escuelas, calles y plazas que llevaran el nombre de este militar y de otros ejecutores de las campañas militares contra los indígenas, para remover sus monumentos o, simplemente, como en el caso de la ciudad de General Roca en la 
provincia de Rio Negro la iniciativa popular consagró el cambio de su nombre por el toponímico mapuche para la zona, Fiske Menuko.

4 En 2010 desde la Red de Investigadores en Genocidio y Política Indígena le ofrecimos a Osvaldo armar una compilación con trabajos nuestros, reescritos con fines de difusión, en un libro prologado por él para continuar su serie "Historia de la crueldad argentina" que se había iniciado en el Centro Cultural de la Cooperación con un volumen que revisaba la política de la generación del ‘ 80 en relación con los inmigrantes y las clases obreras. Miguel Leuman, un referente mapuche que trabajaba en CTERA - uno de los principales sindicatos docentes del país-, consiguió el apoyo de una mutual de la provincia de Buenos Aires para costear la primera edición. "Historia de la crueldad 2: Julio A. Roca y el genocidio de los pueblos originarios" surgió entonces para denunciar el genocidio y a la vez responder a las celebraciones acríticas del Bicentenario patrio que se dieron por esos días. El libro tuvo gran repercusión, especialmente entre los trabajadores de la educación y militantes por los derechos humanos.

Osvaldo Bayer nació en Santa Fe, el 18 de febrero de 1927. Sus padres fueron José Gaspar Bayer y Albina Elisa Colombo, argentinos hijos de inmigrantes, colonos en Santa Fe. José Gaspar, un activo socialdemócrata y antinazi, fue inspector de Correos y Telégrafos, por lo cual la familia debió vivir sucesivamente en Colonia Humboldt, Tucumán, Río Gallegos, y en la Ciudad de Buenos Aires.

6 Anarquista, pacifista, romántico, obstinado, dedicó su vida a investigar y denunciar las injusticias y abusos contra los obreros, los pueblos originarios, los migrantes, las mujeres, los activistas políticos, los desposeídos. Por sus ideales humanistas, se negó a hacer el servicio militar pero, lejos de obtener lo pretendido, fue destinado a barrer y encerar los pisos de los despachos de los oficiales durante dieciocho meses. Al salir, comenzó a estudiar medicina y filosofía en la Universidad de Buenos Aires, pero la censura creciente lo decidió a viajar, en 1952, a Alemania, adonde lo esperaba su novia Marlies Joos, escritora y por entonces estudiante de periodismo. Osvaldo se graduó en Historia en la Universidad de Hamburgo, donde ejerció la docencia. Estudió también periodismo, según sus palabras, para hallar un lenguaje que le permitiera potenciar la comunicación pública de la Historia. En 1956 volvió a Buenos Aires junto a Marlies y el mayor de sus hijos, Udo.

7 A lo largo de su vida estudió exhaustivamente la historia del movimiento obrero y especialmente su vertiente anarquista en Argentina. Publicó, Severino Di Giovanni, el idealista de la violencia (1970 y Los anarquistas expropiadores y otros ensayos (1975), entre otras obras.

8 Su rigurosa investigación sobre los fusilamientos de alrededor de mil quinientos peones en Santa Cruz en 1921 fue amasada durante más de diez años y aun hoy resulta un trabajo ejemplar. Publicó las primeras notas sobre el caso en la revista Todo es Historia, fundada por Félix Luna. Los tres primeros tomos de Los vengadores de la Patagonia Trágica se editaron entre 1972 y 1974 . El cuarto tomo del ensayo debió esperar a 1978 para publicarse en Alemania por el exilio forzado del autor y del editor. Bayer reconoció haber tenido una primera aproximación a los hechos a través de La Patagonia Trágica, la obra de José M. Borrero publicada ya en 1928, pero su investigación logró establecer con mayor objetividad y profundidad los contextos en que se produjeron los hechos de violencia como las responsabilidades del gobierno de Hipólito Yrigoyen como de los empresarios extranjeros, nacionales y las fuerzas vivas locales. Mientras el trabajo de Borrero limitaba la responsabilidad al ejecutor militar y a la Sociedad Rural, Bayer no se 
abstuvo de señalar la participación de sectores -que hoy llamaríamos- progresistas en la masacre, y su complicidad con los sectores económicos que decían combatir. Esta honestidad trascendental y característica de su obra le atrajo a lo largo de su vida tantas enemistades como devociones. Sufrió exilios, prohibiciones, la quema de sus libros, persecución y cárcel por parte de todas las dictaduras militares y también de varios gobiernos democráticos.

9 La gran difusión lograda por su trabajo sobre la huelga de los peones del 21 y su represión, lejos de limitarse a la narrativa del pasado, sigue aun produciendo efectos en las localidades donde hoy se están levantando monumentos a los caídos. Al volver del exilio, Bayer impulsó la búsqueda de las fosas comunes, con el objetivo de señalar los lugares donde se había producido la huelga y la represión, y rescatar los restos de las víctimas. A las puertas del centenario de la masacre, este reto que hoy procura especialmente la organización Ruta de la Huelga, cobró especial impulso a partir de la querella iniciada en 2014 por Aurora López, nonagenaria hija de Alejo, uno de los fusilados.

Si hay algo que caracterizó a Osvaldo Bayer es su audacia para transgredir los límites del registro asignado al trabajo profesional del historiador. Así, su vocación se explayó en géneros y ámbitos diversos. Además de sus trabajos históricos y periodísticos, publicó en clave testimonial Rebeldía y esperanza (1993); Rainer y Minou (2001), novela sobre el amor, la memoria, la responsabilidad histórica y la culpa ambientada en el escenario de la posguerra alemana; un libro de poemas, Los cantos de la sed (2015). "Nadie describió el exilio como vos", dijo emocionado Juan Gelman luego de leer una nota de Bayer sobre la experiencia sufrida. Así nació la idea de Exilio (1984), el libro que reúne textos de ambos.

11 Escribió guiones para varias películas, basadas en sus investigaciones sobre la historia reciente y el pasado violento de la Argentina. Entre ellas La Maffia (1972, con José Dominiani y Leopoldo Torre Nilsson); Todo es ausencia (1983, documental sobre las Madres de Plaza de Mayo filmado durante la dictadura por Rodolfo Kuhn), Juan: como si nada hubiera sucedido (1987, con Carlos Echeverría), La amiga (1988), Fútbol argentino (1990, con Lita Stantic), Jaime de Nevares: último viaje (1995, con Carmen Guarini), Mártir o asesino (2008), Awka Liwen (2010, con Mariano Aiello) y Simón hijo del pueblo (2013, con Rolando Goldman).

Pero el más recordado de sus guiones cinematográficos es el de La Patagonia Rebelde, la película de H. Olivera y F. Ayala estrenada en 1974 y prohibida pocos meses después. Por un acuerdo de prudencia entre los productores, había quedado afuera de la película el último episodio del guión, conocido como el de "las putas de San Julián". Bayer se prometió a sí mismo que en algún momento publicaría la historia censurada. En 2013 se integró como actor y autor en la versión teatral homónima de Rubén Mosquera. A sus casi 90 años y semanalmente, Osvaldo recorrió salas dispares con esta obra, para recordar a aquellas heroínas que desde la más extrema vulnerabilidad habían tenido el solitario coraje de rechazar a los asesinos de los huelguistas de Santa Cruz. Al mismo tiempo, el Quinteto Negro La Boca estrenaba su álbum Tangos Libertarios, que reúne doce tangos y algún vals, todos con letra de Osvaldo Bayer y música del Quinteto Negro La Boca, uno de los cuales es, precisamente, Las putas de San Julián.

En 1958, luego de trabajar para Noticias Gráficas, Osvaldo Bayer se había radicado con su familia en Esquel (provincia de Chubut) empleándose como redactor en el diario local. Por diferencias en el contenido y el tono de sus notas, fue despedido del medio, y 
como intimidación se le armó una causa por tentativa de homicidio contra el dueño del diario, por la cual fue encarcelado unos días. Sin embargo, en lugar de irse de la localidad, decidió quedarse y redoblar la apuesta, fundando junto a Juan Carlos Chayep el periódico "La ChIsPa" -en alusión a la traducción de Iskra, el diario fundado por Lenin en 1900 cuyo lema era "Una chispa puede encender el fuego": el lema de La ChIsPa de Bayer era "Contra el latifundio. Contra el hambre. Contra la injusticia". En sus pocos meses de vida, las páginas de $\mathrm{La}$ ChIsPa, reproducidas artesanalmente y con pocos recursos, denunciaron casos de despojo territorial de familias indígenas. En particular, las maniobras por las cuales los herederos de Rafael Nahuelquir, a pesar de haber pagado por sus propias tierras en la localidad de Cushamen (una de las comunidades mapuches más extensas de la región), fueron estafados por un legislador del partido radical y otros particulares, que provocaron la pérdida sus tierras a manos de éstos y de la Compañía de Tierras del Sud Argentino S. A., actualmente propiedad del empresario Benetton.

La Gendarmería se ocupó de que Bayer y su familia abandonaran Esquel, aludiendo a una denuncia por filtración de información estratégica en área fronteriza, y por provocar "inquietud en la población". La continuidad hasta hoy de conocidas estructuras locales y nacionales que prolongan la explotación laboral y la estafa territorial, otorga a La ChIsPa una vigencia que fue reconocida cuando a mediados de 2017 el propio Osvaldo pudo presentar la versión facsimilar compilada y editada por Bruno Napoli. “Curiñanco y Nahuelquir” tituló Bayer una nota en el diario Página 12, el 5 de junio de 2004, acerca de la vigencia de los reclamos territoriales de esta familia mapuche contra el estanciero Benetton. La "cuestión mapuche" llegó a las primeras planas de los diarios en 2017, cuando la represión estatal del conflicto, en ese mismo lugar, produjo el asesinato de Santiago Maldonado por agentes de Gendarmería.

Expulsado de Esquel y de nuevo en Buenos Aires, desde 1958 trabajó en la redacción del diario Clarín hasta que en 1971 fue "desplazado" al suplemento cultural, al que llegó a dirigir y rebautizó Cultura y Nación. El motivo de la sanción fue la publicación de la que él mismo consideró su mejor nota en ese medio: "Una súplica en la noche", la denuncia del maltrato a los niños de la calle en la estación Constitución por parte de algunos empleados del subterráneo.

Fue Secretario general del Sindicato de Prensa entre 1959 y 1962. SiPreBA lo nombró Secretario honorario.

En 1974 el periodista Rogelio García Lupo lo alertó de que el grupo parapolicial Triple A (Alianza Anticomunista Argentina) lo había marcado. Osvaldo no dimensionó en un primer momento la gravedad de la amenaza, pero logró que su esposa Marlies y sus cuatro hijos se refugiaran primero en Uruguay, y más tarde en Alemania. Luego Bayer logró salir del país con la ayuda de la Embajada alemana. Con su trabajo como traductora y como profesora de español, Marlies sostuvo la economía y la integridad familiar durante la proscripción y el exilio de Osvaldo.

La película Cuarentena, de Carlos Echeverría, documentó en tiempo real los dilemas del retorno de Bayer y otros exiliados que se presentaron con el fin de la dictadura y la apartura democrática en la Argentina en 1983, con sus familias divididas, la pobreza inminente, el trabajo esquivo y la falta de garantías personales. En la película puede verse la búsqueda infructuosa de Bayer por distintas redacciones -de las cuales al principio sólo la revista Humor respondió favorablemente- y su solidaridad con las agrupaciones de DDHH y especialmente Madres de Plaza de Mayo, en tiempos preelectorales en que todavía ningún candidato, a excepción de Oscar Alende, 
contemplaba el juzgamiento de los jerarcas militares en su plataforma. Osvaldo no era un extraño para las Madres, dado que estando en Europa había difundido su situación y había conseguido fondos de la Iglesia Ortodoxa y del Partido Verde Alemán para que ellas pudieran viajar a denunciar a la dictadura.

Pocos años después empezó a colaborar en el diario Página 12, donde su firma terminó siendo una marca singular. Sus contratapas se convirtieron en un clásico de los sábados. Por ellas desfilaron sus preocupaciones por la política internacional y la denuncia de la explotación y la violencia en diferentes casos del mundo. También allí se dieron a conocer pequeñas y grandes iniciativas en el campo de la cultura, se anunciaron marchas y eventos del activismo por los derechos humanos $\mathrm{y}$, específicamente, de los derechos de los pueblos originarios.

En el patio de El Tugurio -tal el nombre que Osvaldo Soriano consagró para la casa de Bayer, situada en la esquina de Arcos y Monroe en el barrio de Belgrano de la ciudad de Buenos Aires, en la que falleció y en la que había pasado parte de su infancia- se gestaron libros, películas y exposiciones, pero especialmente se sostuvo la lucha de compañeros muy diversos. Por El Tugurio desfilaban diariamente artistas, periodistas, académicos, políticos, activistas de múltiples luchas, jóvenes y curiosos. Todos éramos recibidos y todos llevábamos nuestros temas y nuestros delirios, que Bayer pacientemente escuchaba y comentaba.

16 Lejos de mantenerse intramuros, Bayer fue un incansable visitador de escuelas, cárceles, pueblos, talleres. Respondía a todas las invitaciones, gastaba sus días en micros y aviones para promover lo que llamaba la lectura ética de la historia. A pesar de su avanzada edad, la firma de libros que le acercaban sus lectores al finalizar alguna charla podía prolongarse horas, pero no dejaba a nadie sin su dedicatoria personal y distinta. Su sentido del humor sorprendía en medio de la recordación de páginas dramáticas de su vida o de la historia, tanto como seducía su pasión inextinguible en la búsqueda de la verdad y la justicia.

17 En los últimos años, empezó a tomar más fuerza entre todas esas luchas, la de la llamada "desmonumentalización" de Roca y los genocidas de los pueblos originarios.

"Desmonumentar" no significa, para quienes compartimos ese proyecto, apenas remover monumentos, sino modificar la estructura ideológica que construye próceres para los genocidios y oscurece las luchas por la liberación de los pueblos.

Los representantes reciclados de la vieja oligarquía comprendieron la profundidad de la propuesta y reaccionaron en consecuencia. A las muchas editoriales y columnas de opinión publicadas en el diario conservador La Nación contra la "amenaza indigenista" representada por Bayer, se sumó en 2011 la demanda civil que la familia Martinez de Hoz -la misma que contribuyó con un Ministro de Economía a la dictadura de Videla- le inició por mancillar "el buen nombre y honor" de la familia. En la demanda, el punto de conflicto era la afirmación de Osvaldo en la película Awka Liwen, de que la familia Martinez de Hoz se habían visto beneficiados con 2,5 millones de hectáreas por su aporte económico al ejército durante la llamada Campaña al Desierto. Los Martínez de Hoz exigían la retractación de Osvaldo en una solicitada pública, y una indemnización de 500.000 \$ por parte de la producción de la película, además del retiro de la misma de todas las salas, o que se cortara los fragmentos que aludían a la familia. Finalmente, después de cinco años el tribunal falló a favor de Bayer y de los productores, por considerar que el mecanismo de censura que pretendía la familia Martínez de Hoz 
configuraría un perjuicio a un interés más alto, tal como el derecho a la libre expresión, símbolo de la democracia recuperada contra las dictaduras representadas en la línea genealógica Roca - Videla - Martínez de Hoz.

A lo largo de su vida Bayer supo reunir buenos amigos y compañeros de lucha. Expresaba cierta culpa por haber sobrevivido a Rodolfo Walsh, a Paco Urondo, a Haroldo Conti. Formó un equipo irreductible con León Rozitchner, Osvaldo Soriano, Rogelio García Lupo, Juan Gelman, Tito Cossa, Fernando Birri, Blanca Rébori. Recibió la solidaridad de Herman Schiller, de Adolfo Pérez Esquivel y de Beinusz Szmukler en momentos críticos, y fundó con Graciela Daleo y Marcelo Ferreira la primera Cátedra Libre de Derechos Humanos, en la Facultad de Filosofía y Letras de la UBA, en 1994, como desafío directo a la amnesia oficial decretada desde el gobierno neoliberal.

A lo largo de un siglo de mala memoria y cíclicos oscurantismos, Osvaldo Bayer sostuvo la posibilidad de aunar el profesionalismo en la investigación, con el compromiso político y humanista, y una rara capacidad para la comunicación. Esto lo convirtió, especialmente en la última década, en una figura inusualmente popular, con la capacidad de despertar devociones en sitios dispares del espectro político y social. Entrar a la Feria del Libro, o a una escuela, o caminar por la calle con Osvaldo del brazo implicaba detenerse cada minuto para que firmara un autógrafo, recibiera un abrazo, un beso, o declaraciones de amor anónimo.

En sus últimos años, Bayer se repartió entre el verano porteño con la militancia y el verano en Linz am Rhein (Alemania) con su familia. La intimidad de ese transcurrir escindido entre distintas pasiones fue captada en la película La Livertá, de Gustavo Gzain. En 2015 el fallecimiento de su esposa lo erosionó profundamente y, sumado a la aparición y avance de una enfermedad, determinó el fin de sus viajes. En la modesta casa familiar del barrio de Belgrano, entre sus paredes que rebalsan de libros y sus pilas de papeles, Osvaldo continuó recibiendo incesantes visitas, acompañado a veces por sus hijos Udo, Esteban, Cristian y Ana que viajaban desde Alemania o Italia, y más frecuentemente por sus amigos inclaudicables, en particular, Raúl Fernández y Claudia Toledo y su esposo Julio, pero también su médica Carlota Salomón, Ana María Careaga, Cecilia Rosetto, Soledad Iparraguirre, Bruno Napoli, Néstor Elías, Jorgelina Mendez, Laura Jara Suazo, Irma Caupan, Eduardo Kozanlian, Mariana Dufour, Karina Diaz, Oscar Ciancio, Calica Ferrer, Stella Calloni, Norita Cortiñas, Tati Almeida y otros que espero disculpen mi olvido.

En medio de la aridez y la amargura que en los últimos tiempos acompañaron el avance de los modelos totalitarios en la región, las personas como Osvaldo Bayer crean oasis de solidaridad y empatía con los menos privilegiados. Ojalá la "actitud Bayer" nos acompañe largamente en el camino del compromiso con la ética y la alegría.

\section{NOTES}

1. Agradezco a Raúl Fernández sus generosos aportes sobre el borrador de este texto. 


\section{AUTHOR}

DIANA LENTON

CONICET - Universidad de Buenos Aires

dianalenton@gmail.com 